\title{
Clinical Research in Finance
}

\author{
Rajan Bahadur Paudel
}

\begin{abstract}
This paper attempts to shed light on the new approach of research in finance: clinical approach. This approach is based on these four paradigms: functionalist, interpretative, radical humanist and radical structuralist. The thrust of this paper is to inculcate the concept and paradigms of this new approach of research methodology in the mind of researchers.
\end{abstract}

WITH THE EVER CHANGING issues in finance, the research methodology in finance is also changing. Earlier researches in finance are based on functionalist paradigm and follow scientific research methodology. But current researchers are increasingly adopting other paradigm and are attracted towards clinical methodology. Therefore, this paper briefly discusses clinical research methodology in finance and the paradigms in social science research.

\section{Scientific Methodology Versus Clinical Methodology}

The methodology traditionally favoured in the study of social science is called scientific research methodology. It begins with the observation of the phenomenon, and is based on the idea that the researcher observes what is out there. Reality is the source of idea in scientific methodology. The principal stages of scientific methodology consist of the following (Morgan 1983):

1. observation

2. theory building

3. hypothesis: systematic doubt

4. experimental framework/design, and

5. test: rejection, reformulation or confirmation of the theory.

The clinical methodology starts with the idea that one should attempt to understand the reality from inside. For that matter the clinical scientist should take the role of a learner rather than that of an expert. As a learner the clinical analyst keeps rigorous documentation of the scientist's observations and action within the phenomenon. In practical terms, the researcher has to visit, observe, listen, interact and prepare journal of what people are seeing and saying from their standpoint. The researcher is then required to identify the key themes and interpret the situation. This is similar to theory building, stage 2, of the scientific methodology. In clinical methodology it is delayed until stage 4 because it believes that the theory should not be brought in from outside, but make sense from inside. The clinical scientist attempts to explain how reality is constructed. Therefore, the methodology used should be compatible with the internal mechanisms of this reality construction process. Finally the researcher tests the validity of the theory by bringing systematic doubt into the explanations and themes. Morgan (Morgan 1983) puts these stages in the following order: 1. get inside: get deeply involved in the situation

2. adopt the role of learner

3. map the system of symbols and their meanings

4. identify key themes and explanations, and

5. test against opinion in the situation: reject, reformulate, or confirm themes and explanations. 


\section{The Journal of Nepalese Business Studies}

Some authors regard clinical research as a complement to or a stage in the scientific method, while others claim it as an independent research methodology on its own terms. Authors also differ on what guides the choice of the research methodology i.e., scientific methodology versus clinical methodology. For some, it is the research questions; but some others see a need to examine the important relationship between paradigms (world view) and methodologies (implying paradigm of the researcher guides the selection of the research methodology). Paradigms provide researchers not only with the map but also with directions essential for map-making. The following section briefly describes about paradigms.

\section{Paradigms}

Paradigm can be considered the same as world view, or way of seeing reality. It refers to implicit and/or explicit views of reality. It can be defined and characterised by a set of fundamental assumptions. Thus paradigms are based on different assumptions about the nature of science and the nature of the society. Social theory can usefully be conceived in terms of four key paradigms. The four paradigms are:

1. functionalist paradigm

2. interpretative paradigm

3. radical humanist paradigm, and

4. radical structuralist paradigm.

Each of the four paradigms implies a different way of social theorizing in general and finance in particular. These four paradigms are of paramount importance to any scientists because the knowledge of paradigms makes scientists aware of the boundaries within which they approach their subject.

\subsection{The Functionalist Paradigm}

The functionalist paradigm assumes that society has a concrete existence and follows a certain order. These assumptions lead to the existence of an objective and value-free social science that can produce true explanatory and predictive knowledge of the reality. It assumes that

$\Uparrow \quad$ scientific theories can be assessed objectively by reference to empirical evidence,

$\Uparrow \quad$ there are universal standards of science, which determine what constitutes an adequate explanation of what is observed,

$\Uparrow \quad$ there are external rules and regulations governing the external world,

$\Uparrow \quad$ scientists do not see any role for themselves within the phenomenon that they analyze, and

$\Uparrow \quad$ the goal of the scientist is to find orders that prevail within that phenomenon.

The functionalist paradigm seeks to provide rational explanations of social affairs. It emphasizes the importance of understanding order, equilibrium and stability in society and the way in which these can be maintained. It is concerned with the regulation and control of social affairs.

The world of finance is treated as a place of concrete reality, characterised by uniformities and regularities which can be understood and explained in terms of cause and effects. Based on these assumptions the current theories in finance are clearly based on the functionalist paradigm.

\subsection{The Interpretive Paradigm}

The interpretive paradigm sees the social world as a process that is created by individuals. Social reality, insofar as it exists outside the consciousness of any individual, is 
regarded as being a network of assumptions and inter-subjectively shared meanings. These assumptions lead to the belief that there are shared multiple realities which are sustained and changed. The goal of interpretive researcher is to find out the orders that prevail within the phenomenon under consideration.

The interpretive paradigm believes that scientific knowledge is socially constructed and socially sustained; its significance and meaning can only be understood within its immediate social context. Interpretative finance research enables scientists to examine aggregate market behaviour together with ethical, cultural, political and social issues. The interpretative paradigm believes that there are no universally valid rules of finance and financial management. Interpretative research in academic finance is negligible compared to the functionalist research.

\subsection{The Radical Humanist Paradigm}

The radical humanist paradigm assumes that reality is socially created and sustained. It provides critiques of the status quo. It tends to view society as anti-human. It views the process of reality creation as feeding back on itself; such that individual and society are prevented from reaching their highest potential. That is, the consciousness of human beings is dominated by the ideological superstructures of the social system which results in their alienation or false consciousness. This, in turn, prevents true human fulfilment.

Radical humanists believe that everything must be grasped as a whole, because the whole dominates the parts in an all-embracing sense. Moreover, truth is historically specific, relative to a given set of circumstances, so that one should not search for generalizations for the laws of the motion of the society. Radical humanist research in academic finance is nonexistent.

\subsection{The Radical Structuralist Paradigm}

The radical structuralist paradigm assumes that reality is objective and concrete. It uses scientific methods to find the order that prevails in the phenomenon. It views society as a potentially dominating force. This paradigm is based on four central notions. First, there is the notion of totality. The notion emphasizes that the totality shapes and is present in all its constituent parts. Second, there is the notion of structure. The focus is upon the configurations of social relationships, called structure. The third notion is that of contradiction. Structures, or social formations, contain contradictory and antagonistic relationships within them that act as seeds of their own decay. The fourth notion is that of crisis. Contradictions within a given totality reach a point at which they can no longer be contained. The resulting economic and political crises indicate the point of transformation from one totality to another, in which one set of structures is replaced by another of a fundamentally different nature. Radical structuralist research in academic finance is nonexistent.

\section{REFERENCES}

Ardalan, Kavous.2003. Theories and Controversies in Finance: A Pragmatic Overview. International Journal of Social Economics. 30: 199-209.

Ardalan, Kavous.2003. Money and Academic Finance: The Role of Paradigms. International Journal of Social Economics 30: 720-740.

Ardalan, Kavous.2003. On Clinical Research in Finance. International Journal of Social Economics 30: $1038-48$. Easterby-Smith, Mark, Richard Thorpe, and Andy Lowe. 2003. Management Research - An Intorduction. London: Sage Publication.

Morgan, G. 1983. Beyond Method: Strategies for Social Research. Beverly Hills, CA: Sage Publications. Myers, Stewart. 1999. Financial Architecture. European Financial management 5: 133-41. 